\title{
MORBIDITY PROFILE OF PATIENTS REPORTING AT A RURAL HEALTH TRAINING CENTRE IN A TRIBAL AREA.
}

KEY WORDS: Morbidity profile, OPD, Tribal area.

\section{Dr Chinmay N \\ Golkhale \\ Dr Smita S \\ Chavhan*}

\section{Dr Balkrishna B}

Adsul

Dr Kirti V Kinge Assistant Professor, Community Medicine, HBTMC \& Dr RNCH,Mumbai.

Assistant Professor, Community Medicine, HBTMC \& Dr RNCH, Mumbai.

Associate Professor, Community Medicine, HBTMC \& Dr RNCH, Mumbai. *Corresponding Author

Professor, Community Medicine,LTMMC and GH, Mumbai.

Introduction: Primary health care was defined at Alma Ata international Conference with 8 essential elements. Most of our country's population lives in rural area and it has always been a challenge to provide all these elements of Primary Health care to them especially in tribal areas.

Aims \& Objectives: This study was carried out to observe the morbidity profile of patients reporting in routine OPD at Rural Health Training Centre situated in a tribal area.

Methods: This study was conducted at a Rural Health Training Centre (RHTC) in Palghar, Maharashtra. Data of all patients was collected for a period of one year between Jan 2019 and Dec 2019. Data was entered and analyzed using Microsoft Excel Spreadsheet software.

Results and Observations: A total of 25503 patients reported to OPD of Rural Health Training Centre in the study year of 2019. Out of these $72 \%$ were adults. The monthly trend of diseases showed two peaks in seasons of monsoon (predominantly AFI) and winters (mostly URTI).

Conclusion: This study showed that various illnesses have seasonal variations and also there is scope for better reporting of definitive diagnoses. Such studies at regular intervals may provide a better picture in terms of health care needs of patients of tribal areas and may help upgrading services.

\section{INTRODUCTION:}

Primary Health Care has been defined at Alma Ata international conference as "Essential health care made universally accessible to individuals and acceptable to them, through their full participation and at a cost the community and country can afford." Of the 8 essential components (Elements) of Primary Health Care, two are directly concerned with care of illnesses i.e. 'Prevention and Control of locally endemic diseases' and 'Provision of Essential Drugs. ${ }^{(1)}$

In our country the health system has a three tier structure with the Primary Health Centre being a chief point of first contact for the rural population. Also, around $70 \%$ of population of our country lives in rural area, thereby making the health care delivery in rural area an important agenda for any level (union, state, district, tehsil or village) of government. ${ }^{(2)}$ Hence, it is of utmost importance to review the pattern of diseases occurring in the rural population. One of the ways of achieving this is by reviewing disease patterns at Primary Health Centres which are situated at the peripheral village level and are thereby closer to people living in rural areas.

Rural health Training Centres are essential components of medical education in our country. Mostly Rural Health Training Centres are upgraded on existing Primary Health Centres. ${ }^{(3)}$ This study was also planned at a newly initialized Rural Health Training Centre upgraded over an existing Primary Health Centre to analyze the morbidity pattern of patients and the referral services provided to them.

\section{AIMS \& OBJECTIVES:}

This study was carried out to observe the morbidity profile of patients reporting in routine OPD at Rural Health Training Centre situated in a tribal area.

\section{METHODS:}

This study was conducted at Rural Health Training Centre (RHTC) in Palghar District of Maharashtra. Data of all patients was collected for a period of one year between Jan 2019 and
Dec 2019.Details of all patients reporting to RHTC without any exclusion criteria were considered for this study. Morbidities were collected on basis of diagnosis made by the doctor (like Acute Febrile Illness, Acute Gastro Enteritis, etc.) Patients less than 14 completed years of age were considered as Paediatric age group and those above this age were labelled as adults. Data was entered and analyzed using Microsoft Excel Spreadsheet software.

\section{RESULTS AND OBSERVATIONS:}

The Rural Health Training Centre (RHTC) where this study was carried out has 6 sub-centres, one of them being situated in the campus of RHTC/PHC itself. A total of 25503 patients reported to OPD of Rural Health Training Centre in the study year of 2019. Out of these $18360(72 \%)$ were adults and rest $7143(28 \%)$ belonged to paediatric age group. $13953(54.7 \%)$ patients were males while rest 11551 (45.3\%) were females. Amongst adults the male-female proportions were 9980 and 8380 respectively while among paediatric age group the gender ratio was 3972 males and 3171 females. Table 1 shows the distribution of patients that attended RHTC. The monthly total shows that there are two peaks clearly visible in seasons of monsoon (July - August) and winters (January - February and October - December). There is a visible dip in OPD attendance in the summer months of April-June.

Table 2 shows monthly trends of individual diseases. Upper \& Lower Respiratory Infections (URTI \& LRTI respectively) are visibly more in winter months (Jan, Feb, Nov and Dec). Acute febrile Illness and Acute Gastroenteritis cases show a peak during monsoon months. (Jun - Sept). Other diseases like Gatro Esophegeal Reflux Disorders (GERD), MusculoSkeletal disorders (MSK) and non communicable diseases like Diabetes Mellitus (DM) and Hypertension (HT'N) show almost similar number of cases with not much monthly variations. The numbers of cases of STI/UTI (Sexually Transmitted Illness and Urinary Tract Infection) and cases with confirmed diagnosis of Dengue/Malaria/Typhoid were very less throughout the year. A significant number of cases 
were classified as others which included dog bite, Road Traffic Accidents, Injuries, etc.

\section{DISCUSSION:}

This study was carried out in the pre-pandemic year of 2019 to assess the turnout and diversification of patients reporting to a tribal Rural Health Training Centre. The study showed that there are obvious seasonal variations in trends of individual diseases. A low turnout during summer season may have been due to the fact that migrants residing in this study area are known to visit their home towns in summer season owing to routine summer vacation in their children's schools.

Proportion of adults was about $72 \%$ which is lesser than similar previous study. The most common form of illnesses reported included Upper respiratory infections, Acute Febrile illnesses and Musculo-Skeletal disorders. Similar previous studies have also reported that respiratory and Musculo-skeletal illnesses were most common. ${ }^{(4)(5)}$

The trend of Acute Febrile illness (AFI) clearly shows that there is a peak in the months of Monsoon season of June-Oct. Similarly cases of Acute Gastro Enteritis (AGE) also showed peak in months of monsoon season. It is an obvious finding that cases of Upper Respiratory Tract Infection (URTI) were more in winter season (Nov - Feb), however another peak was also seen in months of monsoon. This may be due to the cold environment induced by relatively heavier monsoon in this area and also it may be due to the fact that overall the attendance in OPD is more during these months and hence

there is rise in numbers of individual Comorbidities.

The proportion of cases classified as Non Communicable Diseases (Diabetes or Hypertension) is far less as compared to previously published study. ${ }^{(4)(6)}$ This may be due to the fact that there is a tendency to classify patients on basis of acute symptoms like AFI or URTI instead of their chronic illnesses like Diabetes (DM) or Hypertension (HT'N).

\section{CONCLUSION:}

This study was carried out to classify and analyse the Comorbidities of patients reporting to OPD of Rural Health Training Centre. The study showed that various illnesses have seasonal variations. Also, it can be summarized that there is scope for better reporting of definitive diagnoses and also of Non-communicable diseases. Such studies at regular intervals are likely to provide a better picture in terms of health care needs of patients of tribal areas and also in modifying or upgrading services at peripheral centres to match these needs in these under reached areas.

Acknowledgement: We would like to acknowledge the contributions of all members of Dept of Community Medicine, HBTMC \& Dr RNCH and our Rural Health Training Centre who have made contributions in data collection phase of this study.

\section{Funding:Nil}

Conflict of Interest: $\mathrm{Nil}$

Table 1: Month-wise and Gender-wise distribution of patients

\begin{tabular}{|c|c|c|c|c|c|c|c|c|c|c|c|c|c|}
\hline Category & Jan 19 & Feb 19 & Mar 19 & Apr 19 & May 19 & Jun 19 & Jul 19 & Aug 19 & Sep 19 & Oct 19 & Nov 19 & Dec 19 & Total \\
\hline Adult Male & 789 & 813 & 750 & 589 & 596 & 664 & 1191 & 1113 & 791 & 904 & 884 & 896 & $\mathbf{9 9 8 0}$ \\
\hline Adult Female & 682 & 710 & 689 & 550 & 510 & 468 & 937 & 785 & 652 & 805 & 818 & 774 & $\mathbf{8 3 8 0}$ \\
\hline Paediatric Male & 356 & 374 & 294 & 237 & 248 & 228 & 508 & 413 & 262 & 365 & 339 & 348 & $\mathbf{3 9 7 2}$ \\
\hline Paediatric Female & 242 & 276 & 251 & 209 & 186 & 174 & 462 & 343 & 182 & 279 & 275 & 292 & $\mathbf{3 1 7 1}$ \\
\hline Total & $\mathbf{2 0 6 9}$ & $\mathbf{2 1 7 3}$ & $\mathbf{1 9 8 4}$ & $\mathbf{1 5 8 5}$ & $\mathbf{1 5 4 0}$ & $\mathbf{1 5 3 4}$ & $\mathbf{3 0 9 8}$ & $\mathbf{2 6 5 4}$ & $\mathbf{1 8 8 7}$ & $\mathbf{2 3 5 3}$ & $\mathbf{2 3 1 6}$ & $\mathbf{2 3 1 0}$ & $\mathbf{2 5 5 0 3}$ \\
\hline
\end{tabular}

Table 2: Month-wise distribution of Morbidity pattern

\begin{tabular}{|c|c|c|c|c|c|c|c|c|c|c|c|c|c|}
\hline Disease & Jan-19 & Feb-19 & Mar-19 & Apr-19 & May-19 & Jun-19 & Jul-19 & Aug-19 & Sep-19 & Oct-19 & Nov-19 & Dec-19 & Total \\
\hline URTI & 470 & 534 & 401 & 310 & 246 & 211 & 565 & 490 & 393 & 541 & 495 & 658 & 5314 \\
\hline LRTI & 0 & 1 & 0 & 1 & 3 & 0 & 2 & 3 & 1 & 3 & 0 & 3 & 17 \\
\hline AFI & 267 & 348 & 310 & 205 & 228 & 235 & 1150 & 730 & 409 & 415 & 361 & 368 & 5026 \\
\hline AGE & 76 & 106 & 85 & 45 & 75 & 65 & 138 & 71 & 61 & 79 & 64 & 93 & 958 \\
\hline MSK & 333 & 386 & 349 & 250 & 260 & 274 & 425 & 450 & 309 & 368 & 391 & 353 & 4148 \\
\hline GERD & 89 & 106 & 113 & 69 & 97 & 59 & 140 & 153 & 107 & 123 & 132 & 128 & 1316 \\
\hline Skin & 309 & 283 & 219 & 129 & 210 & 242 & 224 & 259 & 255 & 382 & 363 & 249 & 3124 \\
\hline DII & 52 & 30 & 18 & 24 & 21 & 23 & 30 & 51 & 14 & 31 & 14 & 34 & 342 \\
\hline HTN & 38 & 21 & 16 & 32 & 22 & 18 & 21 & 37 & 10 & 29 & 14 & 34 & 292 \\
\hline TB & 5 & 9 & 8 & 9 & 5 & 2 & 9 & 18 & 3 & 18 & 3 & 10 & 99 \\
\hline STI & 4 & 2 & 13 & 2 & 5 & 1 & 11 & 5 & 2 & 8 & 4 & 19 & 76 \\
\hline UTI & 3 & 0 & 2 & 4 & 7 & 0 & 6 & 2 & 3 & 9 & 2 & 11 & 49 \\
\hline Dengue & 0 & 0 & 0 & 0 & 0 & 0 & 1 & 0 & 1 & 1 & 1 & 2 & 6 \\
\hline Typhoid & 0 & 0 & 0 & 1 & 1 & 0 & 2 & 0 & 0 & 0 & 1 & 1 & 6 \\
\hline Malaria & 0 & 0 & 0 & 0 & 0 & 0 & 0 & 0 & 0 & 0 & 1 & 0 & 1 \\
\hline Others & 423 & 347 & 450 & 504 & 360 & 404 & 374 & 385 & 319 & 346 & 470 & 347 & 4729 \\
\hline Total & $\mathbf{2 0 6 9}$ & $\mathbf{2 1 7 3}$ & $\mathbf{1 9 8 4}$ & $\mathbf{1 5 8 5}$ & $\mathbf{1 5 4 0}$ & $\mathbf{1 5 3 4}$ & $\mathbf{3 0 9 8}$ & $\mathbf{2 6 5 4}$ & $\mathbf{1 8 8 7}$ & $\mathbf{2 3 5 3}$ & $\mathbf{2 3 1 6}$ & $\mathbf{2 3 1 0}$ & $\mathbf{2 5 5 0 3}$ \\
\hline
\end{tabular}

REFERENCES:

1. Declaration of Alma-Ata, International Conference on Primary Health Care, Alma-Ata, USSR, 6-12 September 1978. Available at https://www.who.int/ publications/almaata_declaration_en.pdf.Accessed on 30.06.21.

2. Our Census Our future, Census of India, Rural urban Distribution of Population of India, 2011. Ministry of Home Affairs, Govt of India. Available at https://censusindia.gov.in/201 l provresults/paper2/data_files/india/Rural_ urban_2011.pdf.Accessed on 30.06.21.

3. Technical and Operational Guidelines for Rural and Urban Health Training Centre attached with Community Medicine Department of Medical Colleges as per guidelines of Medical Council of India. Indian Association of Preventive and Social Medicine. Available at http://iapsm.org/pdf/ Operational_guidelines\%20for\%20UHTC_RHTC_Final_March_18.pdf. Accessed on 30.06.21.

4. Gupta A, Chellaiyan V, Lohiya A, Rizwan SA, Upadhyay RP and Palanivel C Morbidity Profile of Out-Patients attending a Primary Health Centre in rural Puducherry, South India. National Journal of Community Medicine, 2014:5(4); 424-7.

5. Suleman M. Patterns of health-care utilization and morbidity in a rural community near Lahore, Pakistan. Ann Trop Med Parasitol. 1996 Feb;90(1):79-
85. doi: 10.1080/00034983.1996.11813029. PMID:8729631.

6. Kamaruddin MFB, Noh KM and Jaafar S. Morbidity Profiles at three Primary Care Clinics in Perlis, Malaysia. Med J Malaysia Vol 67 No 4 August 2012 pg $363-368$ 